\title{
Presence of prostate cells in bone marrow biopsies as a sign of micrometastasis in cancer patients
}

\author{
N.P. MURRAY ${ }^{1,2}$, G.M. CALAF ${ }^{3,4}$ and L. BADÍNEZ ${ }^{5}$ \\ ${ }^{1}$ Instituto Nacional de Geriatria; ${ }^{2}$ Facultad de Medicina, Universidad Mayor, Santiago; \\ ${ }^{3}$ Instituto de Alta Investigación, Universidad de Tarapacá, Arica, Chile; ${ }^{4}$ Center for Radiological Research, \\ Columbia University Medical Center, New York, NY, USA; ${ }^{5}$ Instituto Nacional del Cáncer, Santiago, Chile
}

Received August 21, 2008; Accepted November 3, 2008

DOI: $10.3892 /$ or_00000258

\begin{abstract}
The presence of prostate cancer cells in bone marrow of patients with clinically localized disease is associated with increased chance of disease recurrence. The presence of prostate specific antigen (PSA) in bone marrow aspirates has been used to indicate the presence of micrometastasis. The aim of this study was to present a prospective study of prostate cancer patients to determine the presence of cells that express PSA in aspirates taken from bone marrow and to compare with bone marrow biopsy samples. Results indicated a significant difference between the frequency of cells detected in bone marrow aspirate and biopsy samples $(\mathrm{P}<0.0002)$ when all patients were considered. There was no difference between the frequencies of cells detected in bone marrow aspirate and biopsy of patients analyzed before treatment. However, there was a significant $(\mathrm{P}<0.003)$ difference between them after treatment. There was also a significant difference in the frequency of PSA positive cells detected $(\mathrm{P}<0.005)$ in Stages I to IV as well as in the frequency of cells detected $(\mathrm{P}<0.0002)$ when analyzed according to Gleason score. The present results explain the lack of correlation between positive aspirates and prognosis in numerous clinical cases.
\end{abstract}

\section{Introduction}

Prostate cancer is the most common type of cancer in men and the second leading cause of cancer death in Chile with a high incidence of bone metastasis (1). The presence of prostate cancer cells in the bone marrow of patients with clinically localized disease is associated with an increased chance of disease recurrence. However, not all patients develop recurrence. It has been reported that the presence of prostate cells in the bone marrow is associated with disease-

Correspondence to: Dr Nigel P. Murray, Instituto Nacional de Geriatría, José Manuel Infante 370, Providencia, Santiago, Chile E-mail: nigelpetermurray@gmail.com

Key words: micrometastasis, prostate cells, bone marrow aspirates free survival in patients undergoing radical prostate- ctomy (2). These authors evaluated the bone marrow of 86 patients with clinically localized prostate cancer treated by radical prostatectomy for the presence of prostate cells using molecular biology studies.

Prostate cancer cells frequently metastasize to the skeleton, and it has been hypothesized that this environment selectively supports the growth of these tumours. Specifically there is strong evidence that interactions between tumour cells and bone marrow stromal cells play a major role in supporting prostate cancer growth and survival in bone (3). Bone metastasis is incurable and contributes significantly to disease-specific morbidity and mortality. The molecular and cellular mechanisms leading to the development of bone metastasis in prostate cancer remain unclear, but are currently under intensive investigation $(4,5)$. There is a genetic predisposition that makes prostate cancer cells more prone to spread to bone. Bone-derived factors are involved in the development of bone metastasis at the level of the local microenvironment, suggesting interactions between metastatic prostate cancer cells and endothelial cells, osteoblasts and osteoclasts from bone marrow.

The presence of prostate specific antigen (PSA) and cytokeratin positive cells in bone marrow aspirates has been used to indicate the presence of micrometastasis. There is an association with tumor stage, Gleason score and time of biochemical failure in cancer survival $(2,6-8)$. The cells showed the same cytogenetic abnormalities of the original tumor (9). The aim of this study was to present a prospective study of prostate cancer patients to determine the presence of cells that express PSA in bone marrow aspirates and to compare with bone marrow biopsy samples.

\section{Materials and methods}

Prostate cancer patients. A prospective study of prostate cancer patients was performed. The inclusion criteria was a confirmed diagnosis of prostate cancer and a written consent to allow bone marrow aspiration and biopsy with sedation and local anesthesia, without medical contra-indications for the procedure. Bone marrow samples of 71 men with prostate cancer with a mean age of 74.3 (SD \pm 11.54 , range 47-91) years were analyzed from the Institute of Radio-Oncology, 
Table I. PSA protein expression in cells present in bone marrow aspirate (BMA) and biopsy of prostate cancer patients.

A, Total number of patients distributed by stage TNM before and after treatment $(n=71)$

\begin{tabular}{lccc}
\hline $\begin{array}{c}\text { Stage } \\
\text { TNM }\end{array}$ & $\begin{array}{c}\text { Total no. of } \\
\text { patients before } \\
\text { treatment }\end{array}$ & $\begin{array}{c}\text { Total no. of } \\
\text { patients after } \\
\text { treatment }\end{array}$ & $\begin{array}{c}\text { Total no. of } \\
\text { patients }\end{array}$ \\
\hline I & 10 & 9 & 19 \\
II & 17 & 8 & 25 \\
III & 19 & 6 & 25 \\
IV & 1 & 1 & 2 \\
Total & 47 & 24 & 71 \\
\hline
\end{tabular}

NS, non-significant.

B, Comparison between PSA protein expression in cells of bone marrow aspirate (BMA) and biopsy in the total number of prostate cancer patients $(n=71)$

\begin{tabular}{lccc}
\hline & $\begin{array}{c}\text { Positive } \\
\text { bone marrow } \\
\text { biopsy }\end{array}$ & $\begin{array}{c}\text { Negative } \\
\text { bone marrow } \\
\text { biopsy }\end{array}$ & Total \\
\hline BMA & 30 & 3 & 33 \\
Positive & 19 & 19 & 38 \\
Negative & 49 & 22 & 71 \\
Total & & & \\
\hline
\end{tabular}

$\mathrm{P}<0.0002$, Chi-square.

C, Comparison between PSA protein expression in cells of bone marrow aspirate (BMA) and biopsy of total number in prostate cancer patients before treatment $(n=47)$

\begin{tabular}{lccc}
\hline & $\begin{array}{c}\text { Positive } \\
\text { bone marrow } \\
\text { biopsy }\end{array}$ & $\begin{array}{c}\text { Negative } \\
\text { bone marrow } \\
\text { biopsy }\end{array}$ & Total \\
\hline BMA & 24 & 2 & 26 \\
Positive & 16 & 5 & 21 \\
Negative & 40 & 7 & 47 \\
Total & & & \\
\hline
\end{tabular}

NS, non-significant (Two-tail Fisher's test).

$\mathrm{D}$, Comparison between PSA protein expression in cells of bone marrow aspirate (BMA) and biopsy of total number of prostate cancer patients after treatment $(n=24)$

\begin{tabular}{lccr}
\hline & $\begin{array}{c}\text { Positive } \\
\text { prostate } \\
\text { biopsy }\end{array}$ & $\begin{array}{c}\text { Negative } \\
\text { prostate } \\
\text { biopsy }\end{array}$ & Total \\
\hline BMA & & 1 & 7 \\
Positive & 6 & 14 & 17 \\
Negative & 3 & 15 & 24 \\
Total & 9 & & \\
\hline
\end{tabular}

$\mathrm{P}<0.003$, Two-tail Fisher's test.
Table I. Continued

E, Comparison between PSA protein expression in cells of bone marrow aspirate (BMA) and biopsy of total number of prostate cancer patients considering stages (TI-TIV) $(n=72)$

\begin{tabular}{lccc}
\hline Stage & $\begin{array}{c}\text { Positive } \\
\text { BMA }\end{array}$ & $\begin{array}{c}\text { Positive } \\
\text { bone marrow } \\
\text { biopsy }\end{array}$ & Total \\
\hline TI & 5 & 8 & 13 \\
TII & 9 & 16 & 25 \\
TIII & 17 & 13 & 30 \\
TIV & 2 & 1 & 3 \\
Total & 33 & 38 & 71 \\
\hline
\end{tabular}

$\mathrm{P}<0.005$, Chi-square

F, Comparison between PSA protein expression in cells of bone marrow aspirate (BMA) and biopsy of total number of prostate cancer patients considering Gleason score $(\leq 5-8)(n=72)$

\begin{tabular}{lccc}
\hline Gleason & $\begin{array}{c}\text { Positive } \\
\text { BMA }\end{array}$ & $\begin{array}{c}\text { Positive } \\
\text { bone marrow } \\
\text { biopsy }\end{array}$ & Total \\
\hline$\leq 5$ & 16 & 12 & 28 \\
6 & 10 & 15 & 25 \\
7 & 5 & 9 & 14 \\
$\geq 8$ & 2 & 2 & 4 \\
Total & 33 & 38 & 71 \\
\hline
\end{tabular}

$\mathrm{P}<0.002$, Chi-square.

Santiago, Chile and samples used were from January 2005 to August 2007. Forty-seven samples were taken before treatment and 24 samples after treatment. The removal of the samples was prior to definitive treatment or between 6 months and 1 year after definitive treatment, to avoid contamination by cells released at surgery. The exclusion criterion were androgen blockage or systemic therapy. The disease stage and Gleason score were considered. Twenty women undergoing bone marrow aspiration and biopsy for hematological disorders were used as controls. Bone marrow aspirates and biopsies were obtained. We performed two types of exams: i) aspiration of bone marrow $(4 \mathrm{ml})$ from the posterior superior iliac crests collected in EDTA, and removal of blood to obtain mononuclear cells that were separated using Histopaque $^{\circledR} 1,077$ and differential centrifugation according to instruction (Sigma-Aldrich, St. Louis, MO) and ii) removal of fresh biopsy sample smeared onto 2 silanized slides, and the bone core placed into $40 \%$ formalin.

Immunocytochemical studies. Gel differential centrifugation was used to concentrate the sample to remove any fragments of the original sample, allowing only free floating cells or small clumps. The cells were washed in PBS, pH 7.4 and suspended in concentrated autologous plasma for a suspension of two million cells per $\mathrm{ml}$ and $25 \mu \mathrm{l}$ to prepare slides. All slides were air dried for $24 \mathrm{~h}$ and then fixed in 


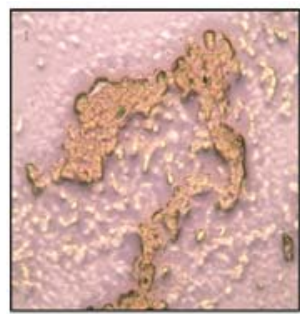

A

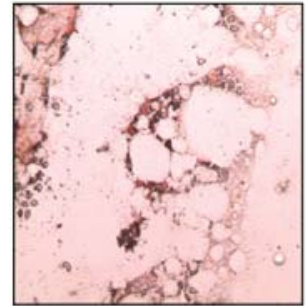

F

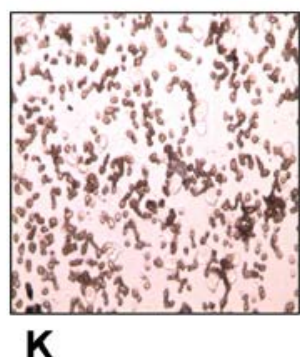

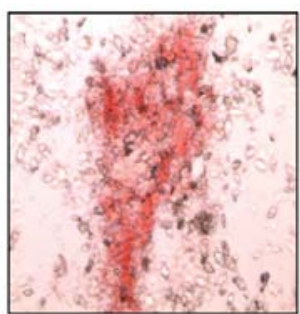

B

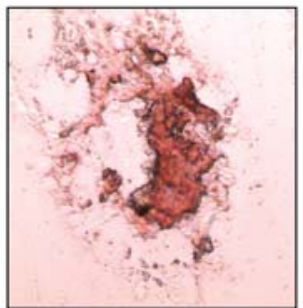

G

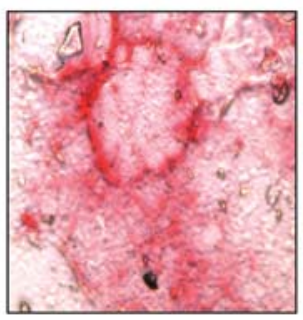

L

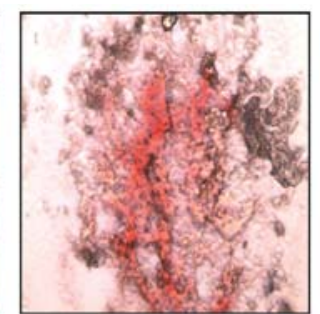

C

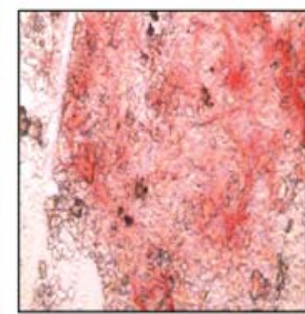

H

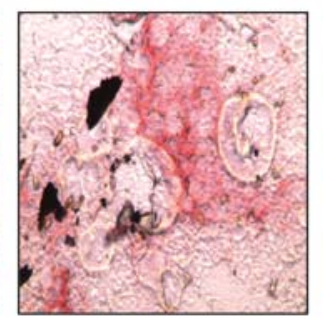

M

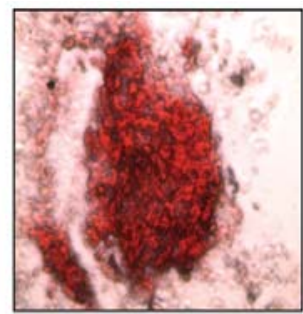

D

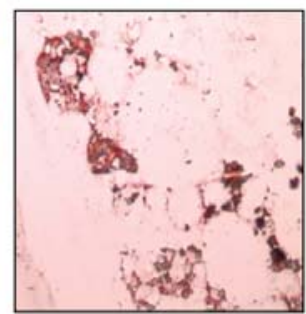

I

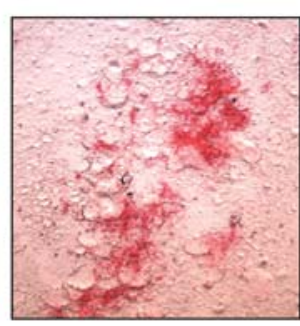

N

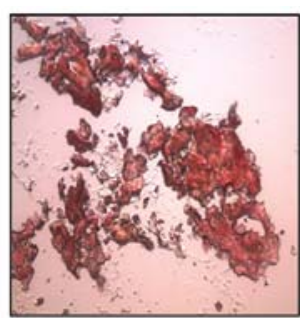

E

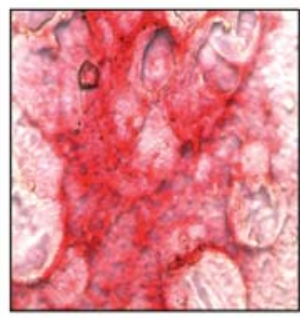

J

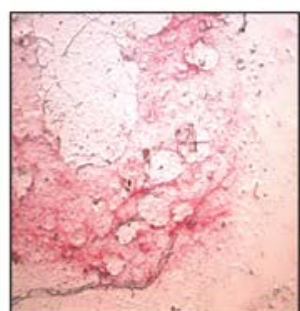

o

Figure 1. Representative images of PSA protein expression in bone marrow biopsies: (A) negative and (B-O) positive cases.

$70 \%$ ethanol, 5\% formalin and 25\% PBS pH 7.4 for 3 min and finally washed in PBS. Monoclonal antibodies against PSA Clone 28A4 at a concentration of $2.5 \mu \mathrm{g} / \mathrm{ml}$ (Novacastra, UK) were incubated at room temperature for $1 \mathrm{~h}$. Prostate cells were identified in the samples by using the LSAB2 kit according the manufacturer's instructions (Dako, USA) based on alkaline phosphatase-antialkaline phosphatase with neofuschin as chromogen. The definition of a prostate cell was a cell with a nucleus staining positive for PSA, based on the criteria of other authors (10). Levamisole (Dako) was used as an endogenous alkaline phosphatase inhibitor. Prostate cells were identified using ocular x10 and objective of $x 10$ and then confirmed with objective x 80 of light microscopy. Photographs were taken using a digital camera (Nikon, Japan).

Statistical analysis. Descriptive statistics were used to analyze demographic features, Chi-squared to compare frequencies and ANOVA for differences in means. An $\alpha$ error of 0.05 , a $\beta$ error of 0.20 and $p<0.05$ was considered statistically significant. For ethical considerations the study was performed in strict accordance with the principles of Helsinki and the modifications of Hong Kong and Venice, and the Chilean Health Ministry's guidelines.

\section{Results}

The presence of circulating prostate cells in bone marrow aspirates as well as in bone marrow of prostate cancer patients was analyzed by determining PSA protein expression. Table I, A-F corresponds to PSA protein expressions in cells present in bone marrow aspirate (BMA) and biopsy of cancer patients.

Table I, A corresponds to total number of patients distributed by stage TNM before $(n=47)$ and after $(n=24)$ treatment. There was no significant difference between the frequencies of cells detected in bone marrow aspirate and biopsy of patients analyzed before treatment. Table I, B shows a comparison between positive or negative PSA protein expression in bone marrow aspirates and biopsies in the total number of prostate cancer patients. Results indicated a significant difference between the frequency of cells detected in bone marrow aspirates and biopsy samples $(\mathrm{P}<0.0002$, Chi-square $)$ when all patients were considered (Table I, B). There was no difference between the frequencies of cells detected in bone marrow aspirates and biopsy of patients analyzed before treatment (Table I, C). However, there was a significant $(\mathrm{P}<0.003)$ difference after treatment (Table I, D) and in the frequency of PSA positive cells detected when Stages from I to IV $(\mathrm{P}<0.005)$ were considered (Table I, E) and also according to Gleason score $(\mathrm{P}<0.0002)$ (Table I, F).

Fig. 1 shows images of PSA protein expression in bone marrow biopsies both negative (A) and positive (B-O) cases. Fig. 2 corresponds to images of PSA protein expression in bone marrow aspirate of prostate cancer patients. Negative cases were observed (A to C), positive smear (D), positive aspirates $(\mathrm{E}-\mathrm{H})$ and bone marrow fragments (I-L). 


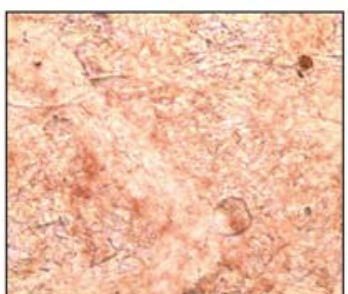

A

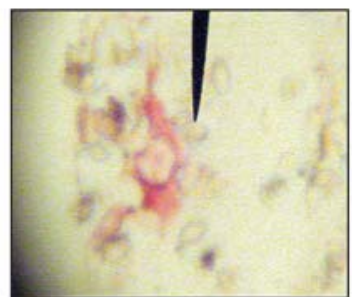

$\mathbf{E}$

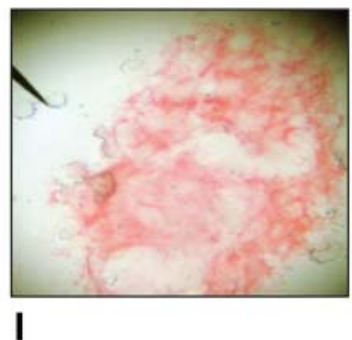

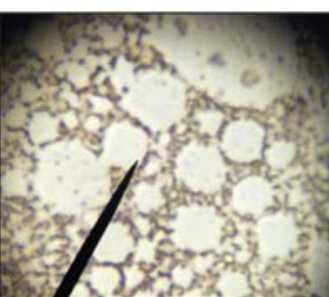

B

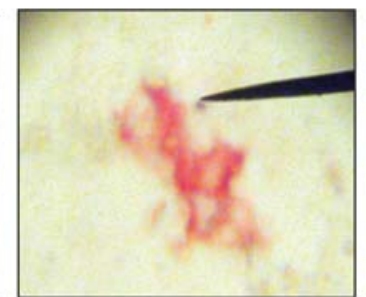

$\mathbf{F}$

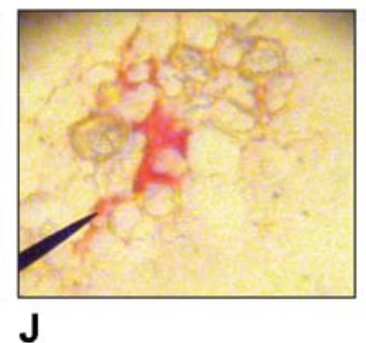

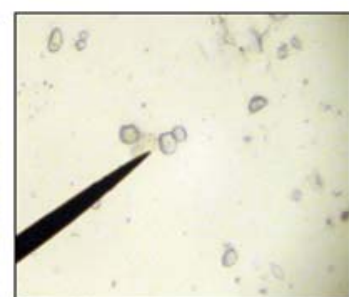

C

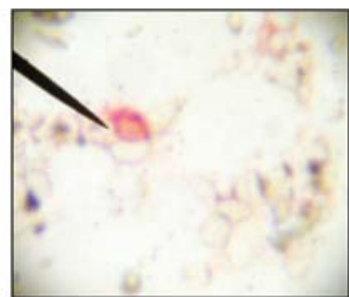

G

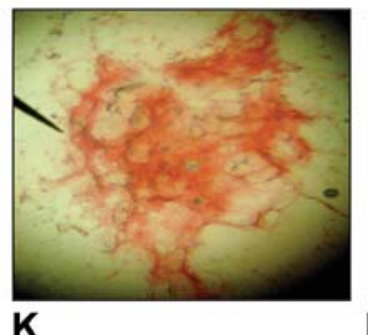

$\mathbf{K}$

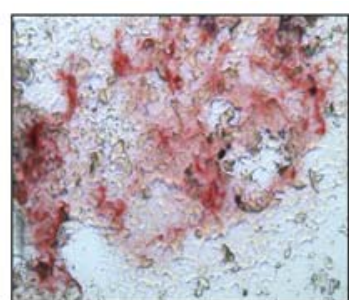

D

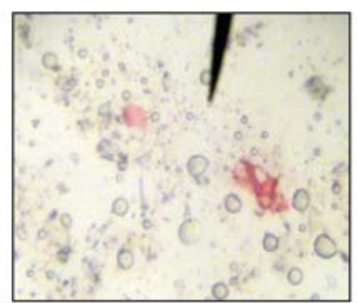

H

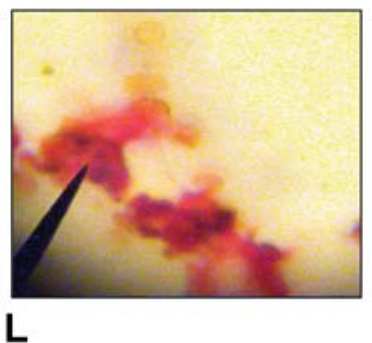

Figure 2. Representative images of PSA protein expression in bone marrow aspirate of cancer prostate patients: (A-C) negative cases, (D) positive smear, (E-H) positive aspirates and (I-L) positive bone marrow fragments.

\section{Discussion}

These studies analyzed the presence of prostate cells in bone marrow aspirates and biopsy samples in order to determine prevalence of micrometastatic cells in the bone marrow of men with histological confirmed prostate cancer. The patients were analyzed by the TNM stage. There was a significant difference in the frequency of detection of PSA expressing cells in aspirate and biopsy when stages were considered. Similar findings have been previously reported for stage TI and TII $(2,6,8,11)$. There was also a significant difference between the frequency of PSA positive cells detected in aspirate and biopsy when analyzed according to Gleason score. There was no significant difference in patients with higher Gleason score. Previous studies have shown a frequency between 23 and $38 \%$ for Gleason score of $\leq 6$ $(6,8,11)$.

To improve cell sample numbers before immunocytochemical detection, samples were concentrated by using gelbased differential centrifugation. This system removes any fragment from the original sample and thus only floating cells or small clumps were analyzed. Bone marrow biopsies are not routinely used for immunochemical detection since the use of standard pathology methods of decalcification destroys many epitopes, thus rendering an immunochemical analysis doubtful as to the presence or absence of specific cell markers. However, the use of 'touch preps' from fresh samples, and analysis of the cellular imprint has been widely used in hematology to obtain a more rapid result, while awaiting formal histology. The use of such touch preps could be important to determine the presence of micrometastasis in bone marrow since it permits the analysis of micro-fragments with immunochemical techniques.

Other studies (7) have shown that prostate micrometastasis have a low proliferating index thus it would be expected that the cells remain adherent to the endostium and not in the intertrabecular spaces, that is negative aspirate and biopsy positive. This suggests that bone marrow aspirates may not truly represent micrometastatic disease due to bone marrow cell kinetics. This may help to explain why patients have a relapse of the disease with negative bone marrow aspirate. It is postulated that a bone marrow aspirate, for its nature, allow to get either a sample of cells that are in transit or a sample that are removed from the endostium. The cells in transit could be circulating from the original tumor, or have detached from proliferating micrometastasis.

There are no studies of in vivo tumor cell rheology in the bone marrow. However, there are in vivo optical imaging studies in laboratory animals to demonstrate the mechanisms of tumor cell attachment to the endostium that are similar to stem cell engraftment $(12,13)$. Topological and chronological patterns of stem cell seeding have shown that most cells drift within the bone marrow space, then are gradually found close to the endosteal surface. The center of the bone marrow space seems to be the site of proliferation of transplanted cells and not the endosteal surface (14). Further studies have shown that the adherent cells are viable, whereas cells in transit contain a percentage of dead or dying cells (15). 
Experimental data suggest that adhesion is the rate limiting determinant of homing and early seeding and a crucial event that preserves the viability of cells towards successful engraftment (15). Since cells attached to the endosteal surface are not usually detected it may explain why not all patients with positive bone marrow aspirate develop metastasis. Conversely, patients with negative bone marrow aspirate may have cancer cells attached to the endosteal surface that later may develop into metastasis. This may explain in part the lack of correlation between positive aspirates and prognosis in some studies $(16,17)$. Results of this study are consistent with this theory. Based on the present studies larger studies are suggested to redefine the concept of bone marrow micrometastasis for only those patients with positive fragments.

\section{Acknowledgements}

We would like to thank Danissa Barahona for her secretarial assistance.

\section{References}

1. Szot J: Epidemiological analysis of mortality caused by solid tumors in the Metropolitan Region, Chile. Rev Med Chil 131: 641-649, 2003

2. Wood DP and Banerjee M: Presence of circulating prostate cells in the bone marrow of patients undergoing radical prostatectomy is predictive of disease free survival. J Clin Oncol 15: 3451-3457, 1997

3. Cross NA, Papageorgiou M and Eaton CL: Bone marrow stromal cells promote growth and survival of prostate cancer cells. Biochem Soc Trans 35: 698-700, 2007.

4. Ye L, Lewis-Russell JM, Kynaston H and Jiang WG: Endogenous bone morphogenetic protein-7 controls the motility of prostate cancer cells through regulation of bone morphogenetic protein antagonists. J Urol 178: 1086-1091, 2007.

5. Ye L, Lewis-Russell JM, Kyanaston HG and Jiang WG: Bone morphogenetic proteins and their receptor signaling in prostate cancer. Histol Histopathol 22: 1129-1147, 2007.
6. Cher ML, De Oliveira JG, Beaman AA, Nemeth JA, Hussain M and Wood DP Jr: Cellular proliferation and prevalence of micrometastatic cells in the bone marrow of patients with clinically localized prostate cancer. Clin Cancer Res 5: 2421-2425, 1999.

7. Oberneder R, Riesenberg R, Kreigmair M, et al: Immunocytochemical detection and phenotypic characterization of micrometastatic tumor cells in bone marrow of patients with prostate cancer. Urol Res 22: 3-8, 1994.

8. Pantel K, Aignherr C, Köllermann J, Caprano J, Riethmüller G and Köllermann MW: Immunocytochemical detection of isolated tumor cells in bone marrow of patients with untreated stage C prostate cancer. Eur J Cancer 31: A1627-A1632, 1995.

9. Mueller P, Caroll P, Bowers E, et al: Low frequency epithelial cells in bone marrow aspirates from prostate carcinoma patients are cytogenetically aberrant. Cancer 83: 538-546, 1998

10. Borgen G: Standardization of the immunocytochemical detection of cancer cells in bone marrow and blood I: Establishment of objective criteria for the evaluation of immunostained cells ISHAGE. Cytotherapy 5: 377-388, 1999.

11. Murray NP: El costo beneficio del estudio de diseminación en cáncer prostático en el uso de anticuerpos monoclonales para detectar micrometástasis en la médula ósea: una comparación con el cintigrama óseo. Rev Chil Urol 71: 200-204, 2006.

12. Askenasy N and Farkas DL: Optical imaging of PKH-labeled hematopoietic cells in recipient bone marrow in vivo. Stem Cells 20: 501-513, 2002.

13. Quesenberry PJ and Becker PS: Stem cell homing: rolling, crawling and nesting. Proc Natl Acad Sci USA 95: 15155-15157, 1998.

14. Christensen JL, Wright DE, Wagers AJ and Weissman IL: Circulation and chemotaxis of fetal hematopoietic stem cells. PLoS Biol 2: E75, 2004

15. Mazo IB and Von Andrian UH: Adhesion and homing of bloodborne cells in bone marrow microvessels. J Leukoc Biol 66: 25-32, 1999.

16. Morrisey $\mathrm{C}$ and Vessella RI: The role of tumor micro-environment in prostate cancer bone metastasis. J Cell Biochem 101: 873-886, 2007.

17. Depuy V, Anstrom KJ, Castel LD, Schulman KA, Weinfurt KP and Saed F: Effects of skeletal morbidities on longitudinal patients reported outcomes and survival in patients with metastatic prostate cancer. Support Care Cancer 15: 869-876, 2007. 